Provided for non-commercial research and education use. Not for reproduction, distribution or commercial use.

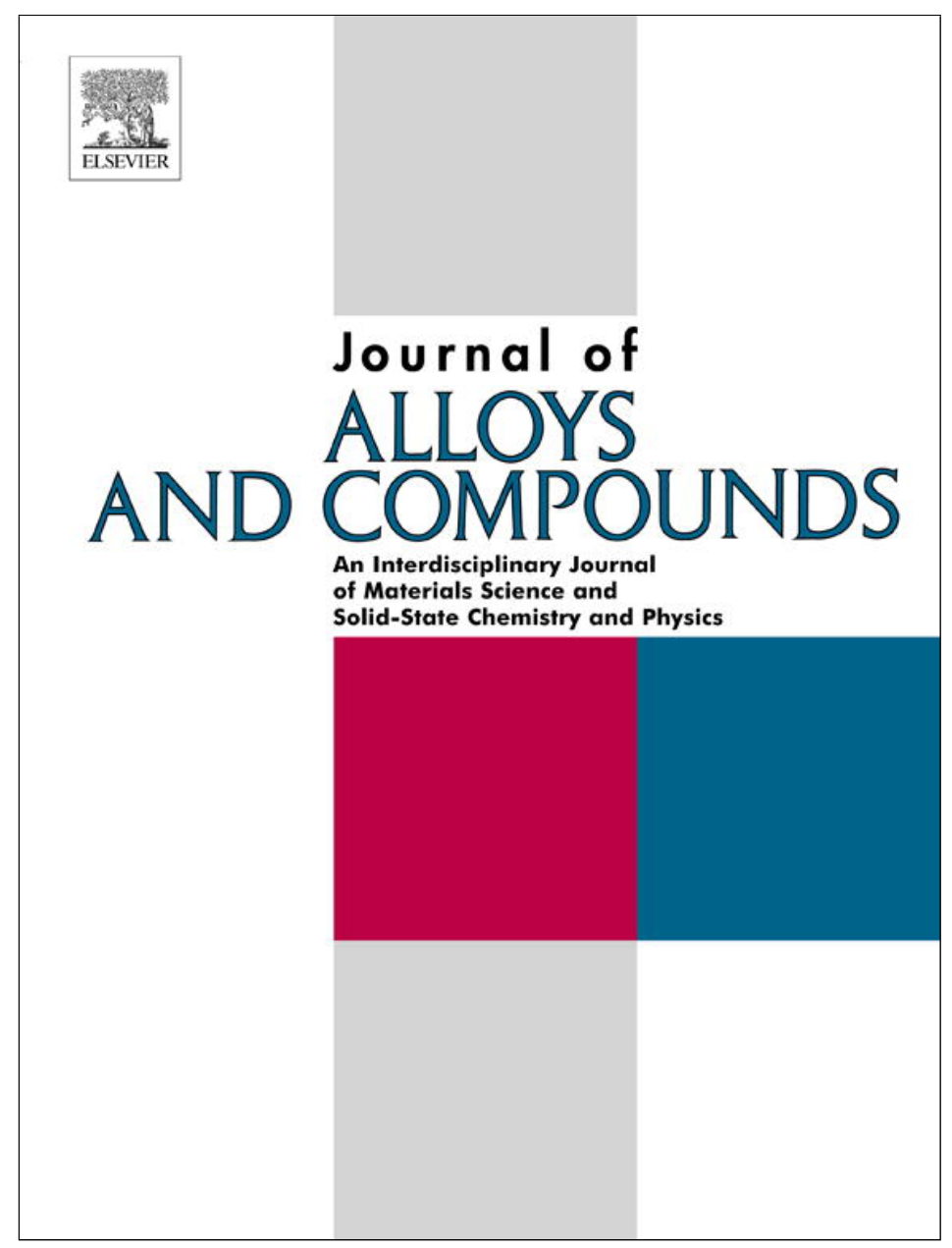

This article appeared in a journal published by Elsevier. The attached copy is furnished to the author for internal non-commercial research and education use, including for instruction at the authors institution and sharing with colleagues.

Other uses, including reproduction and distribution, or selling or licensing copies, or posting to personal, institutional or third party websites are prohibited.

In most cases authors are permitted to post their version of the article (e.g. in Word or Tex form) to their personal website or institutional repository. Authors requiring further information regarding Elsevier's archiving and manuscript policies are encouraged to visit:

http://www.elsevier.com/authorsrights 


\title{
In situ observation of the phase selection from the undercooled melt in $\mathrm{Cu}-\mathrm{Zr}$
}

\author{
J. Gegner ${ }^{\mathrm{a}, *}$, O. Shuleshova ${ }^{\mathrm{b}}$, R. Kobold ${ }^{\mathrm{a}}$, D. Holland-Moritz ${ }^{\mathrm{a}}$, F. Yang ${ }^{\mathrm{a}}$, W. Hornfeck ${ }^{\mathrm{a}}$, J. Bednarcik ${ }^{\mathrm{c}}$, \\ D.M. Herlach ${ }^{\text {a }}$
}

${ }^{a}$ Institut für Materialphysik im Weltraum, Deutsches Zentrum für Luft und Raumfahrt (DLR), D-51170 Köln, Germany

${ }^{\mathrm{b}}$ Institut für komplexe Materialien, Leibnitz Institut für Festkörperforschung, Postfach 270116, D-01171 Dresden, Germany

${ }^{\mathrm{c}}$ Deutsches Elektronensynchrotron DESY, Notkestr. 85, D-22603 Hamburg, Germany

\section{A R T I C L E I N F O}

\section{Article history:}

Received 9 November 2012

Received in revised form 25 March 2013

Accepted 5 April 2013

Available online 13 April 2013

\section{Keywords:}

Metallic glasses

Rapid solidification

Crystal structure

X-ray diffraction

\begin{abstract}
A B S T R A C T
The phase selection of intermetallic $\mathrm{Cu}_{50} \mathrm{Zr}_{50}$ and of eutectic $\mathrm{Cu}_{46} \mathrm{Zr}_{54}$ have been investigated by in situ high energy synchrotron X-ray diffraction on electrostatically levitated samples. No change in the selected primary phase over the whole accessible undercooling range for both compositions is found. In the case of $\mathrm{Cu}_{50} \mathrm{Zr}_{50}$ the primary phase is always of B2-type for undercoolings up to $310 \mathrm{~K}$. $\mathrm{Cu}_{46} \mathrm{Zr}_{54}$ always solidifies as a combination of $\mathrm{CuZr}(B 2)$ and $\mathrm{CuZr} \mathrm{r}_{2}\left(C 11_{b}\right)$. For $\mathrm{Cu}_{50} \mathrm{Zr}_{50}$ the temperature dependence of the lattice constant is reported.
\end{abstract}

(c) 2013 Elsevier B.V. All rights reserved.

\section{Introduction}

$\mathrm{Cu}-\mathrm{Zr}$ alloys have attracted broad interest because of their ability to form so-called bulk metallic glasses [1,2]. Wang et al. [3] have shown that with electrostatic levitation technique it is possible, due to the absence of container walls that could act as nucleation centers, to undercool the melt of $\mathrm{Cu}_{50} \mathrm{Zr}_{50}$ to very large undercoolings $\Delta T$ below the liquidus temperature $T_{L}$. With undercoolings of up to $325 \mathrm{~K}$, even the hypercooling regime can be reached. Their analysis of the growth velocity reveals an unusual behavior for binary alloys. At an undercooling of $\approx 200 \mathrm{~K}$ the growth velocity reaches a maximum with relatively small values of $\approx 25 \mathrm{~mm} / \mathrm{s}$. At higher undercoolings, the growth velocity decreases. The usual behavior for binary alloys is that the growth velocity increases monotonously with increasing amount of undercooling.

There are several crystallographic phases involved at a composition around 50 at\% Zr. It is commonly accepted that the CuZr B2 phase is not stable at room temperature. According to Massalski [4] it decomposes into $\mathrm{Cu}_{10} \mathrm{Zr}_{7}$ and the $\mathrm{CuZr}_{2}$ at $988 \mathrm{~K}$. Other authors report on additional phases that occur like $\mathrm{Cu}_{8} \mathrm{Zr}_{3}, \mathrm{Cu}_{5} \mathrm{Zr}_{8}$, $\mathrm{Cu}_{51} \mathrm{Zr}_{14}$ [5-7]. If rapidly quenched, CuZr undergoes a martensitic transition from $B 2$ to $B 19^{\prime}$ and $B 33$ [8].

\footnotetext{
* Corresponding author. Tel.: +4922036012138.

E-mail address: jan.gegner@dlr.de (J. Gegner).
}

Since it is possible to undercool liquid $\mathrm{Cu}-\mathrm{Zr}$ below the transition temperature of $988 \mathrm{~K}$, it is not clear which phase is adopted in the primary solidification event that takes place at conditions far from equilibrium. For $\mathrm{Fe}_{60} \mathrm{Co}_{40}$ [9] and $\mathrm{Fe}-\mathrm{Ni}-\mathrm{Cr}$ [10] it has been shown that the change of the growth velocity with undercooling directly correlates with a change of the adopted crystal structure. Kwon et al. have proposed that the high glass forming ability of $\mathrm{Cu}-\mathrm{Zr}$ is a result of the competition between the crystallization of different complex intermetallic compounds [11].

Previous experiments have reported on the phase selection by devitrification of the amorphous solid [12], the effect of different heat treatment on the crystal structure [8], and on the short-range order of the liquid $[13,14]$. In this paper, we report on in situ measurements of the phase selection $\mathrm{Cu}-\mathrm{Zr}$. Containerless sample processing using electrostatic levitation technique is combined with $\mathrm{X}$-ray diffraction using high energy synchrotron radiation. The recording of complete diffraction patterns within time intervals of less than one second enables to directly observe phase formation during rapid solidification of the undercooled melt.

\section{Experimental details}

Samples of approximately $100 \mathrm{mg}$ in mass were prepared by arc melting the alloy constituents (99.999 at\% $\mathrm{Cu}$ and 99.95 at\% $\mathrm{Zr}$ ) in an $\mathrm{Ar} 6 \mathrm{~N}$ atmosphere. For further purification of the gas, the Ar was pass through an Oxisorb cartridge and a Ti specimen was melted prior to arc melting of each sample as a getter for residual contaminants of the gas. 
By mass analysis of the constituents before and after arc melting, the initial composition of the samples was within 0.05 at\% of the nominal composition. By evaporation during processing of the samples the mass loss was smaller than $0.2 \mathrm{mg}$ for all samples. Thus the maximum deviation from the nominal composition cannot be larger than 0.2 at\%.

The samples were processed using a mobile electrostatic levitation device (ESL) previously used for neutron diffraction experiments [15]. The ESL was installed at the BW5 beamline of Hasylab at DESY. The vacuum level in the sample environment was in the low $10^{-6}$ mbar range. Samples were heated above the melting point by two lasers from opposite directions to up to $1700 \mathrm{~K}$. Subsequently the lasers were switched off and by radiation heat loss the samples cooled freely until spontaneous nucleation sets in. The sample temperature was measured pyrometrically, using the reported liquidus temperatures [4] $T_{L}$ for calibration.

For the time resolved diffraction measurements the photon energy was set to $100 \mathrm{keV}$. The primary beam with a diameter of $1 \mathrm{~mm}$ had to pass through an $\mathrm{Al}$ entrance window of $1 \mathrm{~mm}$ thickness. Scattered light from the entrance window was attenuated by a $1 \mathrm{~mm}$ thick Ta plate with a $5 \mathrm{~mm}$ diameter borehole for the primary beam. A beamstop of $\mathrm{Pb}$ was placed directly after the $5 \mathrm{~mm}$ thick Al exit window to eliminate scattering of the primary beam in air and to absorb the X-rays scattered by the exit window.

The diffraction patterns were recorded in transmission geometry with an Perkin Elmer XRD 1621 image plate detector with $2000 \times 2000$ pixels at a rate of 2 frames per second. The fit2d [16] software was used to reduce the image data to onedimensional intensity data and for calibration. For the calibration of the detector, the diffraction pattern of ${\mathrm{a} \mathrm{LaB}_{6}}_{6}$ sample was used.

\section{Results and discussion}

Fig. 1 shows the melting and solidification cycles of $\mathrm{Cu}_{50} \mathrm{Zr}_{50}$ and $\mathrm{Cu}_{46} \mathrm{Zr}_{54}$ for the highest and the lowest achieved undercoolings. In the upper panels, the temperature-time profile is shown. In the lower panels, the diffracted intensities are shown as a grayscale map as a function of momentum transfer $q$ and time. The achieved undercooling is indicated by the double arrow.

Both $\mathrm{Cu}-\mathrm{Zr}$ samples, the intermetallic compound and the eutectic alloy show a melting plateau in the respective temperaturetime profiles as expected for congruently melting alloys. The small slope is caused by the change of emissivity between the solid and the liquid phase. During melting, the diffraction pattern changes from sharp peaks of the crystalline solid to the rather diffuse pattern of the liquid. When the sample is completely molten, the temperature rises further until the heating laser is switched off. Subsequently, the sample cools down by radiative heat loss and crystallizes spontaneously below the liquidus temperature. This recalescence shows in the temperature-time profile as a sudden jump due to the rapid release of latent heat. At the same time, the diffraction pattern changes from the broad features of the liquid to sharp peaks in the solid. A strong texture leads to the noncontinuous intensities of the diffraction pattern of the $\mathrm{Cu}_{50} \mathrm{Zr}_{50}$ sample solidified at $\Delta T=90 \mathrm{~K}$ (Fig. 1). Both $\mathrm{Cu}-\mathrm{Zr}$ samples, the intermetallic compound and the eutectic alloy show a melting plateau in the respective temperature-time profiles as expected for congruently melting alloys. The small slope is caused by the change of emissivity between the solid and the liquid phase. During melting, the diffraction pattern changes from sharp peaks of the crystalline solid to the rather diffuse pattern of the liquid. When the sample is completely molten, the temperature rises further until the heating laser is switched off. Subsequently, the sample cools down by radiative heat loss and crystallizes spontaneously below the liquidus temperature. This recalescence shows in the temperature-time profile as a sudden jump due to the rapid release of latent heat. At the same time, the diffraction pattern changes from the broad features of the liquid to sharp peaks in the solid. A strong texture leads to the noncontinuous intensities of the diffraction pattern of the $\mathrm{Cu}_{50} \mathrm{Zr}_{50}$ sample solidified at $\Delta T=90 \mathrm{~K}$ (Fig. 1).

The hypercooling limit $\Delta T_{\text {hyp }}$ is defined as $\Delta T_{\text {hyp }}=\Delta H_{f} / C_{L}$ with $H_{f}$ the heat of fusion and $C_{L}$ the specific heat of the liquid under the condition of adiabatic processing. It is shown that the heat loss by radiation during recalescence is small compared with the heat production due to the rapid release of crystallization energy during recalescence [17].

Experimentally, $T_{\text {hyp }}$ can be estimated by the value of $\Delta T$ at which the time span $\Delta t$ of the post-recalescence plateau approaches zero. In Fig. $2 \Delta T$ is plotted versus $\Delta t$ together with linear fitting functions for $\mathrm{Cu}_{50} \mathrm{Zr}_{50}$ and $\mathrm{Cu}_{46} \mathrm{Zr}_{54}$. From the $y$-intercept of the fit, we obtain $\Delta T_{h y p}=(261 \pm 10) \mathrm{K}$ for $\mathrm{Cu}_{50} \mathrm{Zr}_{50}$ and $\Delta T_{\text {hyp }}=(295 \pm 5) \mathrm{K}$ for $\mathrm{Cu}_{46} \mathrm{Zr}_{54}$.

For $\mathrm{Cu}_{50} \mathrm{Zr}_{50}$, the hypercooling regime could be accessed, evident by the absence of a plateau after the recalescence in the right panels of Fig. 1a. In this case the sample solidifies completely during recalescence under non-equilibrium conditions. In contrast, at small undercoolings only a fraction $f_{R} \approx \Delta T / \Delta T_{\text {hyp }}$ of the sample solidifies under non-equilibrium conditions while the remaining part crystallizes under near-equilibrium conditions as indicated by the post-recalescence plateau in Fig. $1 \mathrm{a}$. In the case of $\mathrm{Cu}_{46} \mathrm{Zr}_{54}$ the highest undercooling at which the diffraction pattern could be recorded is at least very close to the hypercooling limit.

For both compositions we achieved a solidification below the transition temperature of $988 \mathrm{~K}$ where the $B 2$-phase is no stable modification. But in both cases we cannot find a change in the adopted crystal structure over the accessible undercooling range.

In the case of $\mathrm{Cu}_{50} \mathrm{Zr}_{50}$ only the B2-phase is formed within the experiment. This is shown in Fig. 3 where the diffraction patterns of $\mathrm{Cu}_{50} \mathrm{Zr}_{50}$ are displayed. The diffraction pattern of the sample solidified at the smallest observed undercooling $\Delta T=90 \mathrm{~K}$ does not differ from the diffraction pattern of the sample that solidified at the highest achieved undercooling of $\Delta T=310 \mathrm{~K}$.
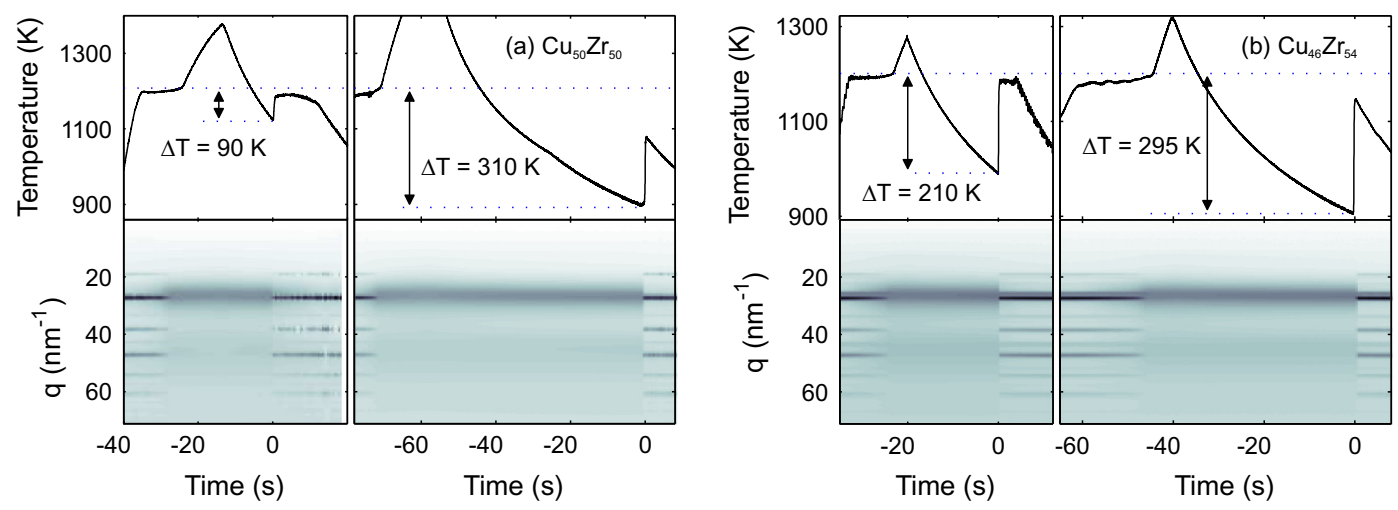

Fig. 1. Melting and solidification cycles of (a) $\mathrm{Cu}_{50} \mathrm{Zr}_{50}$ and (b) $\mathrm{Cu}_{46} \mathrm{Zr}_{54}$ with highest and lowest achieved undercoolings. The upper panels show the temperature-time profiles. The in situ measured diffraction pattern is shown by intensity plots in the lower panels. High intensities are represented by dark gray. The intensity-grayscale mapping is arbitrary and not the same for both figures 


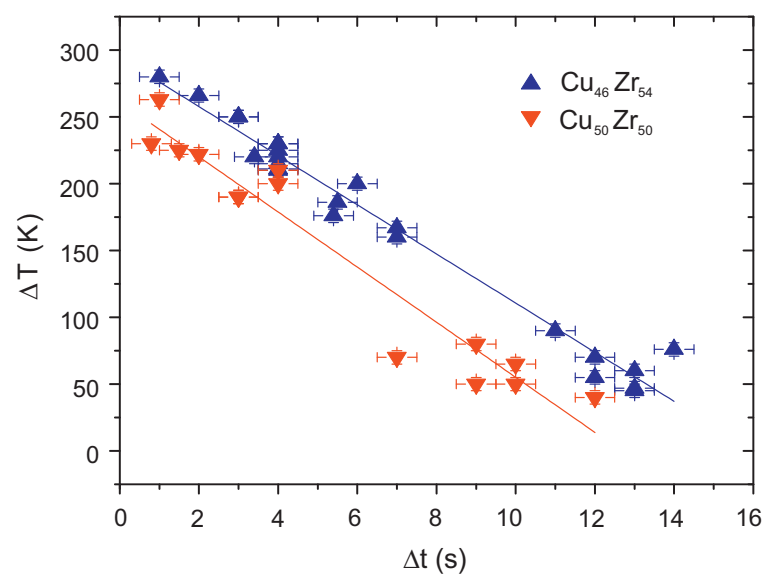

Fig. 2. Undercooling $\Delta T$ vs. the time span of the post-recalescence plateau $\Delta t$ of $\mathrm{Cu}_{50} \mathrm{Zr}_{50}$ and $\mathrm{Cu}_{46} \mathrm{Zr}_{54}$ together with linear fit-functions.

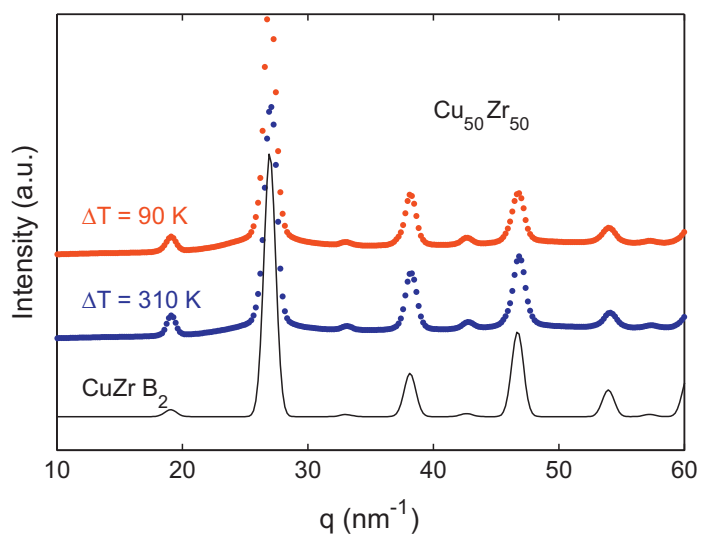

Fig. 3. Diffraction intensities of $\mathrm{Cu}_{50} \mathrm{Zr}_{50}$ for highest and lowest achieved undercooling. In both cases only the $B 2$ phase is adopted as can be seen by comparison with a calculated diffraction pattern for the $B 2$-phase.

For $\mathrm{Cu}_{46} \mathrm{Zr}_{54}$ we also find no change in the adopted crystal structure. Here we find for all achieved undercoolings that the sample solidifies as a combination of the B2-phase of CuZr and the $\mathrm{CuZr}_{2}$ $C 11_{b}$ phase. The diffraction patterns of $\mathrm{Cu}_{46} \mathrm{Zr}_{54}$ solidified at highest and lowest undercooling are displayed in Fig. 4.

Our diffraction measurements do not indicate a change of the adopted crystal structure when the sample is highly undercooled prior to solidification. The possibility remains that other phases are formed in a first stage that might be rapidly destroyed by the rise of temperature during recalescence. In the case that the primary phase transforms much faster than the acquisition rate of $2 \mathrm{~Hz}$ of the X-ray detector we would not be able to detect this with the diffraction measurements. But we would still expect to see a signature of a phase transformation in the temperature signal if the transformation is not faster than the acquisition rate of $100 \mathrm{~Hz}$ of the pyrometer. This is not the case.

In the case of $\mathrm{CuZr}$ it is well possible to determine the lattice parameter from the diffraction patterns as a function of temperature by Rietveld analysis of the diffraction pattern. The resulting lattice parameters are displayed in Fig. 5. The temperature behavior can be well described by a linear function of the temperature $T$ (in K):

$a=0.3246(1) \mathrm{nm}+3.89(6) \times 10^{-6} \frac{\mathrm{nm}}{\mathrm{K}} \times T$.

Applying this formula for room temperature the resulting lattice constant is $a=3.257 \AA$. This result is very close to the value $a=3.2620 \AA$ of Carvalho and Harris [18].

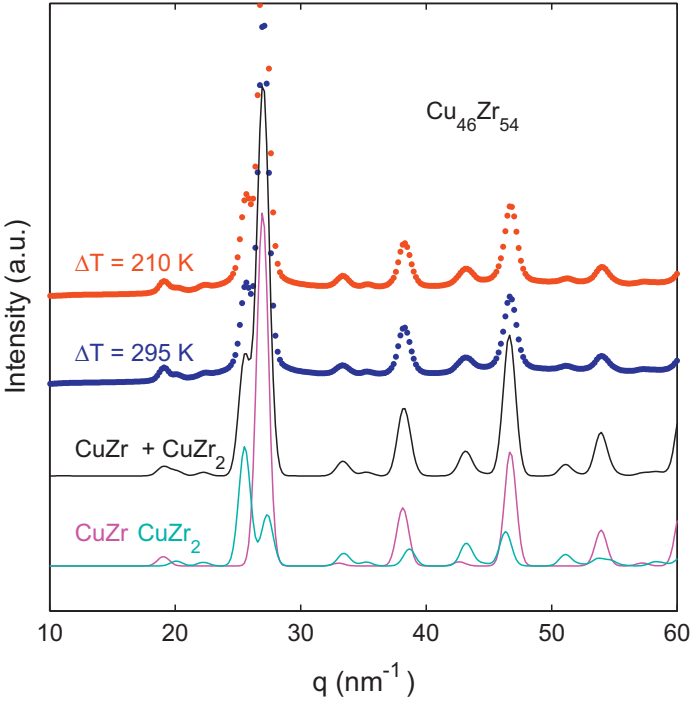

Fig. 4. Diffraction intensities of $\mathrm{Cu}_{46} \mathrm{Zr}_{45}$ for highest $(\Delta T=210 \mathrm{~K})$ and lowest $(\Delta T=295 \mathrm{~K})$ achieved undercooling. In both cases the sample solidifies as a combination of $\mathrm{CuZr}(B 2)$ and $\mathrm{CuZr}_{2}$. The calculated diffraction patterns of $\mathrm{CuZr}$ and $\mathrm{CuZr}_{2}$ are shown below together with their sum.

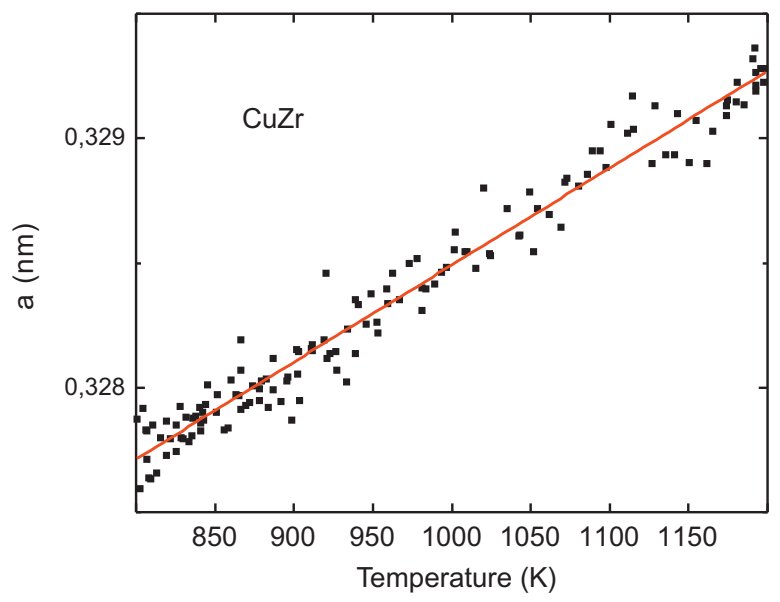

Fig. 5. Temperature dependence of the lattice parameter $a$ of solid CuZr in the temperature range from 800 to $1200 \mathrm{~K}$. The behavior can be well described by a linear fit.

\section{Conclusions}

By containerless electrostatic levitation technique, we were able to undercool the melts $\mathrm{Cu}_{50} \mathrm{Zr}_{50}$ and $\mathrm{Cu}_{46} \mathrm{Zr}_{54}$ by $\Delta T=310 \mathrm{~K}$ and $295 \mathrm{~K}$, respectively. This undercoolings are well below the transition temperature where according to the equilibrium phase diagram [4] $B 2$ is not a stable phase. We have found, that the primary phase adopted under solidification does not change with the increase of undercooling. Both $\mathrm{Cu}-\mathrm{Zr}$ alloys are easy glass forming systems. The excellent glass forming ability has been discussed with respect to phase competition during solidification of the undercooled melt. Apparently according to the present findings no phase changes could be observed during crystallization of the liquid alloys upon undercoolings even beyond the hypercooling limit.

\section{Acknowledgements}

We thank the Deutsche Forschungsgemeinschaft (DFG) for financial support under Contract Number HE1601/26. The authors 
are grateful to F. Kargl for fruitful discussions and A. Meyer for continuous support.

\section{References}

[1] D. Xu, B. Lohwongwatana, G. Duan, W. Johnson, C. Garland, Acta Mater. 52 (2004) 2621.

[2] M. Tang, D. Zhao, M. Pan, W. Wang, Chin. Phys. Lett. 21 (2004) 901.

[3] Q. Wang, L.-M. Wang, M. Ma, S. Binder, T. Volkmann, D.M. Herlach, J. Wang, Q. Xue, Y. Tian, R. Liu, Phys. Rev. B 83 (2011) 14202.

[4] T. Massalski (Ed.), Binary Alloys Phase Diagrams, ASM International, Materials Park, Ohio, 1996.

[5] S. Zhou, R. Napolitano, Acta Mater. 58 (2010) 2186.

[6] W. Gierlotka, K.-C. Zhang, Y.-P. Chang, J. Alloys Comp. 509 (2011) 8313.

[7] N. Wang, C. Li, Z. Du, F. Wang, W. Zhang, CALPHAD 30 (2006) 461.

[8] S. Zhou, R. Napolitano, Scr. Mater. 59 (2008) 1143.
[9] R. Herrmann, W. Lser, G. Lindenkreuz, A. Diefenbach, W. Zahnow, W. Dreier, T. Volkmann, D. Herlach, Mater. Sci. Eng. A 375-377 (2004) 507.

[10] S. Moir, D. Herlach, Acta Mater. 45 (1997) 2827.

[11] O. Kwon, Y. Kim, K. Kim, Y. Lee, E. Fleury, Met. Mater. Int. 12 (2006) 207.

[12] I. Kalay, M.J. Kramer, R.E. Napolitano, Metall. Mater. Trans. A 42a (2011) 1144.

[13] V. Wessels, A. Gangopadhyay, K. Sahu, R.W. Hyers, S. Canepari, J. Rogers, M. Kramer, A. Goldman, D. Robinson, J. Lee, J. Morris, K. Kelton, Phys. Rev. B 83 (2011) 094116.

[14] D. Holland-Moritz, F. Yang, T. Kordel, S. Klein, F. Kargl, J. Gegner, T. Hansen, J. Bednarcik, I. Kaban, O. Shuleshova, N. Mattern, A. Meyer, EPL 100 (2012) 56002.

[15] T. Kordel, D. Holland-Moritz, F. Yang, J. Peters, T. Unruh, T. Hansen, A. Meyer, Phys. Rev. B 83 (2011) 104205.

[16] A. Hammersley, S. Svensson, M. Hanfland, A. Fitch, D. Husermann, High Pressure Res. 14 (1996) 235

[17] D. Herlach, P. Galenko, D. Holland-Moritz (Eds.), Metastable Solids from Undercooled Melts, Pergamon Materials Series, Oxford, 2007.

[18] E. Carvalho, I. Harris, J. Mater. Sci. 15 (1980) 1224. 